\title{
Evapotranspiration: Implementation in NetLogo
}

\author{
Lubna Ansari ${ }^{1}$, Sonal Anand ${ }^{2}$ \\ ${ }^{1,2}$ Assistant Professor, IITM , Janakpuri
}

\begin{abstract}
NetLogo is a popular tool for ABM(Agent Based Modeling). Various models has been developed in NetLogo for understanding and solving many problems. Evapotranspiration is a process combined by two processes i.e. Evaporation and Transpiration. In this paper, we developed a model to calculate the ET for a given condition.
\end{abstract}

Keywords: NetLogo, Evapotranspiration

\section{Introduction}

NETLOGO is a multi Agent programmable modeling environment. It is used by many students, teachers and researchers worldwide. It is authored by Uri Wilensky and developed at CCL(The CCL is a research group headed by Prof. Uri Wilensky. It was founded in 1995).It is specifically capable for modeling complicated systems developing over time. [1] NETLOGO is made up of independent entities which is called Agents.[2] Agents follows the instructions given by the user. [2] The feature that enhances the modeling expressiveness of the NETLOGO is the fact that each agent may be a patch or a turtle can have its own user defined variables.[3] After years of development, NetLogo becomes mature product which is very stable and fast.[4] The main design principle of the multi agent Logos is "Low threshold and no ceiling". [5] Low threshold means new users, who are not a programmer, can easily learn it.[5] No ceiling signifies that the language shouldn't be limiting for advanced users.[5] We have developed an model "Evapotranspiration" using NetLogo.

\section{Why NetLogo?}

After going through many toolkits of agent based modelling, we developed a model for Evapotranspiration in NetLogo.

The reason why, we used NetLogo is because it is very simple to use. There's no need to expertise in any programming language. It has many sample models which help us to understand about the working of NetLogo. It is fast enough. The documentation of NetLogo is very simple and vast. If the user does not know about anything Agent Based Modeling, he can also make model in NetLogo. The documentation of the NetLogo is divided into many parts like procedures, commands. Because of which we easily understood the concept.

Firstly, we go through the manual and understands the commands. After that we analyses many models like rumour model, wolf-sheep model. The user interface of NetLogo is very simple. If the user does not much about toolkits or software, he too can use and understands it. Since it is a open source software, user can download it very easily. It is also not that heavy application. It is light weight application which do not eat up the resources.
Because of all the above reasons we use choose NetLogo 5.0. In the version 5.0 , the user can create, modify or delete tables and arrays.

We developed a model on Evapotranspiration. It is an ecological based model. Before describing our model, we would like to give a brief introduction about Evapotranspiration, as it is non-computer term.

\section{Evapotranspiration}

Evapotranspiration is made up of two terms. One is evaporation and second one is transpiration.

Evaporation: Evaporation is a process by which the water accumulated in the water bodies like river, oceans due to the sunlight converted into vapours.

Transpiration: Transpiration is somewhat similar to evaporation. In transpiration the water content in the plants and human bodies is converted into vapours. When we combine these two terms we get one term which is known as Evapotranspiration.

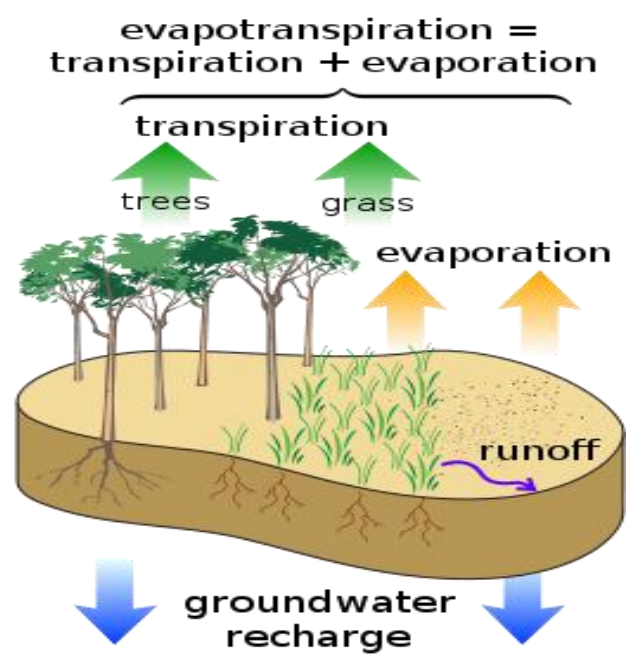

The Evapotranspiration can be represented as ET.[6] The units of Evapotranspiration rate is normally expressed in millimetres (mm) per unit time.[6] This rate implies the amount of water lost from a surface of plants in units of water depth. [6] The time unit can be an hour, month, day, decade, or even an entire growing period or year.[6] 


\section{International Journal of Science and Research (IJSR) \\ ISSN (Online): 2319-7064}

Index Copernicus Value (2015): 78.96 | Impact Factor (2015): 6.391

\subsection{Factors affecting Evapotranspiration}

There are various factors which effects the

Evapotranspiration:

1) Weather parameters: The main weather parameters which effects affecting Evapotranspiration are radiation, air temperature, wind speed and humidity.[6] Many procedures have been developed to calculate the value of ET from these parameters. [6] The evaporation power of the atmosphere is expressed by the reference crop Evapotranspiration $\left(\mathrm{ET}_{\mathrm{o}}\right)$.[6]

2) Crop parameters: The crop type, variety and development stage are considered when calculating the Evapotranspiration from crops grown in large fields. [6] Difference in transpiration rate, crop height, reflection, crop roughness, ground cover and crop rooting properties produces different ET in different types of crops under identical environmental conditions.[6] Crop Evapotranspiration under standard conditions is expressed as $\left(\mathrm{ET}_{\mathrm{c}}\right) \cdot[6]$

3) Management and environmental parameters: these includes parameters like soil salinity, the presence of hard or impenetrable soil horizons, the absence of control of diseases, limited application of fertilizers and pests, poor land fertility, and poor soil management.[6]

\subsection{Evapotranspiration Concepts}

\section{Reference crop Evapotranspiration $\left(\mathbf{E T}_{\mathbf{0}}\right)$}

The Evapotranspiration rate from a reference surface is called the reference crop Evapotranspiration or reference Evapotranspiration and is denoted as $\mathrm{ET}_{\mathrm{o}}$. [6] It is affected by the climatic parameters $\mathrm{ET}_{\mathrm{o}} .[6]$

\section{Crop evapotranspiration under standard conditions}

The crop evapotranspiration under standard conditions,

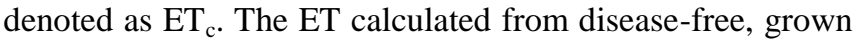
in large fields, well-fertilized crops, under optimum soil water conditions.[6] The ratios of $\mathrm{ET}_{\mathrm{c}} / \mathrm{ET}_{\mathrm{o}}$, called crop coefficients $\left(\mathrm{K}_{\mathrm{c}}\right)$, are used to relate $\mathrm{ET}_{\mathrm{c}}$ to $\mathrm{ET}_{\mathrm{o}}$ or $\mathrm{ET}_{\mathrm{c}}=$ $\mathrm{K}_{\mathrm{c}} \mathrm{ET}_{\mathrm{o}}$.[6]

\subsection{Equations Used}

\subsubsection{Evapotranspiration}

$\mathrm{ET}=\mathrm{I}+\mathrm{P}-\mathrm{RO}-\mathrm{DP}+\mathrm{CR} \pm \square \mathrm{SF} \pm \square \mathrm{SW}$

where, ET is evapotranspiration

I is Irrigation

$\mathrm{P}$ is rainfall

RO is surface runoff

$\mathrm{DP}$ is deep percolation

$\mathrm{CR}$ is capillary rise

SF is subsurface,

SW is soil water content

\subsubsection{Reference Evapotranspiration}

$\mathrm{ET}_{\mathrm{o}}=0.0023\left(\mathrm{~T}_{\text {mean }}+17.8\right)\left(\mathrm{T}_{\max }-\mathrm{T}_{\min }\right)^{0.5} * \mathrm{R}_{\mathrm{a}}$

$\mathrm{ET}_{\mathrm{o}}$ reference evapotranspiration $\left[\mathrm{mm} \mathrm{day}^{-1}\right]$,

$\mathrm{T}_{\text {mean }}$ is mean temperature and can be calculated as,

$\mathrm{T}_{\text {mean }}=\left(\mathrm{T}_{\max }-\mathrm{T}_{\min }\right) / 2$

$\mathrm{T}_{\max }$ is maximum temperature

$\mathrm{T}_{\text {min }}$ is minimum temperature

$R_{a}$ is extraterrestrial radiation

\subsubsection{Crop Evapotranspiration}

$\mathrm{ET}_{\mathrm{c}}=\mathrm{K}_{\mathrm{c}} * \mathrm{ET}_{\mathrm{o}}$

where $\mathrm{K}_{\mathrm{c}}$ is crop coeff which depends on crop type, climate, soil evaporation, crop grown state.

\section{Simulation/ Execution}

Before starting the code, we defined some global variables which we used in our model like ET stores the value of Evapotranspiration, $\mathrm{kc}$ will store the value of crop coeff.

After that, we define a procedure which is linked to the setup button. Whenever we click on setup button, this procedure will start. It colour the patches in blue by pcolor command. It further calls two procedures take-input and use-file.

The next procedure that we design is take-input. In this procedure we took the input from the user which we will use in our calculations. For calculating the value of $k c$ we have to ask the user to give the value of croptype and cropstage. To calculate Tmean we have to take values for Tmin, radiation and Tmax.

The next procedure is go. This procedure is also linked with the button go. It further calls to procedures update-variables and colorup.

The use-file procedure is for importing a file which is in .csv format. This file has the values for $k c$ depending upon the cropstage and croptype. Since these values are in character form we have to convert it in numeric form so that we can use the value of $k c$ in our calculations. After reading the values from the table the value of $k c$ is calculated. This procedure colour the patches. If the ET is less then 15 the colour of the patches remains blue, otherwise it turns black.

The last procedure is update-variables. This procedure on applying the equations of Evapotranspiration calculates the value of $E T, E T_{o}$ and $E T_{c}$.

\section{Snaphots}

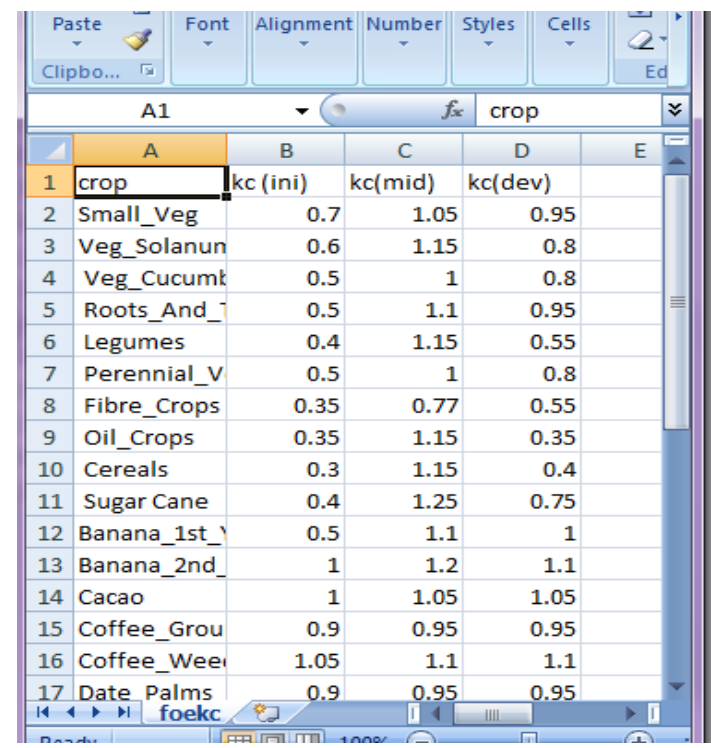

Figure 22: foekc.csv file 


\section{International Journal of Science and Research (IJSR) \\ ISSN (Online): 2319-7064}

Index Copernicus Value (2015): 78.96 | Impact Factor (2015): 6.391

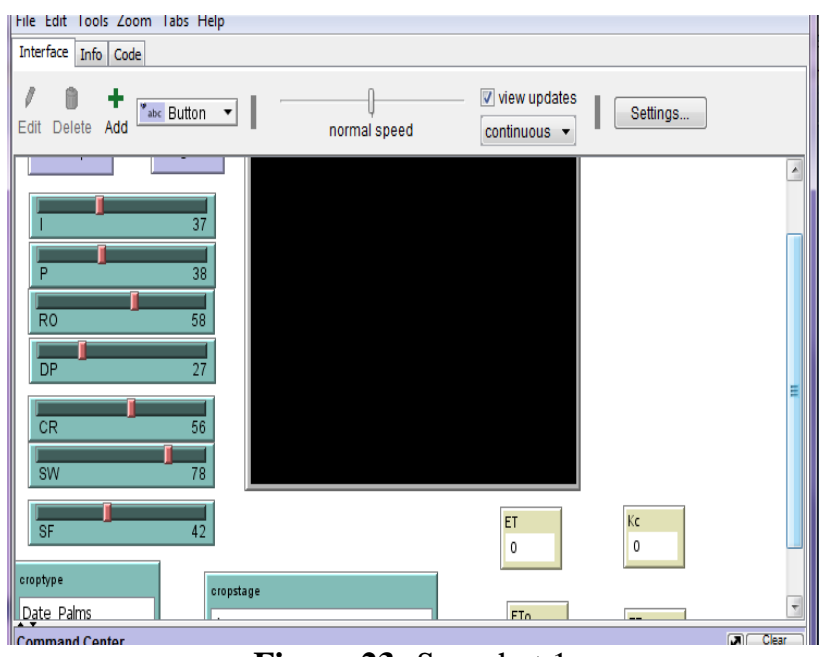

Figure 23: Snapshot 1

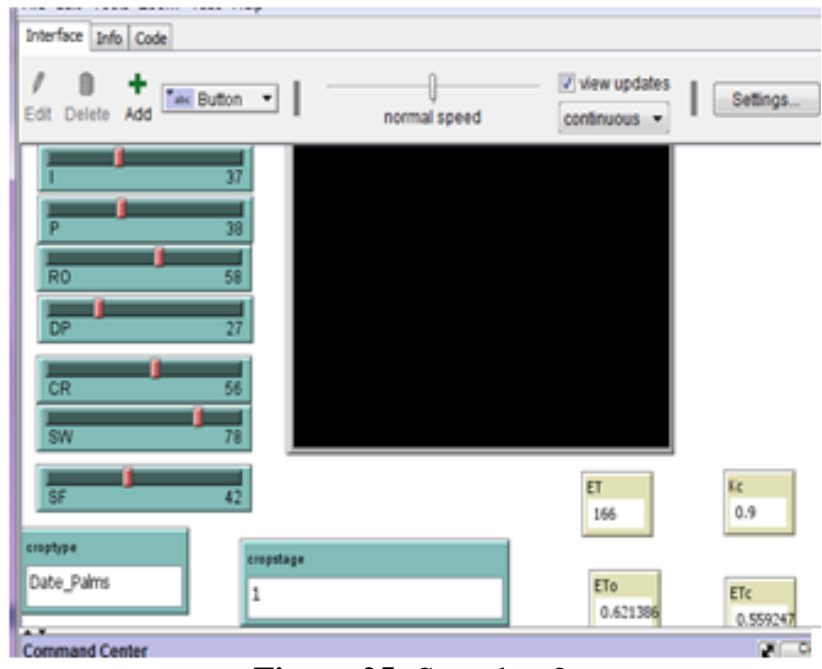

Figure 25: Snapshot 2

\section{Conclusion}

After developing a model in NetLogo, we can conclude that the agent based modelling tools and techniques can be applied to solve the problems of social sciences. Many models are built using these toolkits for the social simulation. Combining these two fields ABM and Social science is very beneficial to the community.

\section{References}

[1] S. Tisue and U. Wilensky, "NetLogo: A Simple Environment for Modeling Complexity," Science Education, pp. 1-10, 2004.

[2] http://ccl.northwestern.edu/netlogo/docs/

[3] I. Sakellariou, P. Kefalas, and I. Stamatopoulou, "Teaching Intelligent Agents using NetLogo," 2008.

[4] S. Tisue, "NetLogo: A Simple Environment for Modeling Complexity," Computer, pp. 1-9.

[5] S. Tisue and U. Wilensky, "NetLogo: Design and Implementation of a Multi-Agent Modeling Environment," Language, 2004.

[6] http://www.fao.org/docrep/x0490e/x0490e04.htm\#chapte r 1 introduction to evapotranspiration

\section{Author Profile}

Ms. Lubna Ansari has done M.Tech (Computer Science) from USICT, GGSIPU and is employed as Assistant Professor in IT at IINTM, GGSIPU, New Delhi, with four years of work experience.

Ms Sonal Anand has done M.Tech(Computer Science) from USICT, GGSIPU and is employed as Assistant Professor in IT at IINTM, GGSIPU, New Delhi, with four years of work experience. 